\title{
Analysis of Dendrochronological Variability and Associated Natural Climates in Eurasia - the last 10,000 years (ADVANCE-10K)
}

Over recent years, with support from the European Union's Climate and Environment Programme and the Swiss National Science Foundation, ADVANCE-10K has brought together some 30 collaborators from 17 institutions, located in 10 European countries. All of these workers share the common goals of gathering, screening, and archiving a mass of primarily Eurasian tree-ring measurements. The ultimate aim is to interpret these data in terms of annually-resolved climate variability; on spatial scales that range from local to near hemispheric and on temporal scales extending over a few hundred to many thousands of years.

One major focus of the project is the continuing development of an extensive network of 'modern' tree-core samples, all taken from relatively cool and moist sites, spread around the northern hemisphere, generally at latitudes above $60^{\circ} \mathrm{N}$, or at higher elevations in more southerly areas. The sites are selected because of the likely sensitivity of local tree growth to climate, specifically temperature, variability. To date, multiple tree-core collections have been made from some 400 sites and the samples processed under the guidance of Fritz
Schweingruber at the Swiss Federal Institute for Forest, Snow and Landscape Research in Birmensdorf, Switzerland, to produce not only ring-width data, but also measurements of intra-annual ring-density. These have enabled firmly dated width and density chronologies to be built with annual resolution for each location, typically spanning 300400 years.

These chronologies are capable of representing detailed patterns of yearby-year temperature anomalies across large areas of the northern continents. Linear transfer functions that relate patterns of recent instrumentally observed summer temperatures to those recorded in the contemporary tree-ring data, provide quantitative temperature estimates, the accuracy of which is demonstrated by comparison with early independent temperature records. The tree-ring network is currently being used to reconstruct a multi-century history of summer temperature changes across northern North America, Europe and, most recently, northern Russia. Though the present sample network extends over the whole of northern Siberia, the greatest concentration of sites and the best temperature reconstruc-

Tornetrask
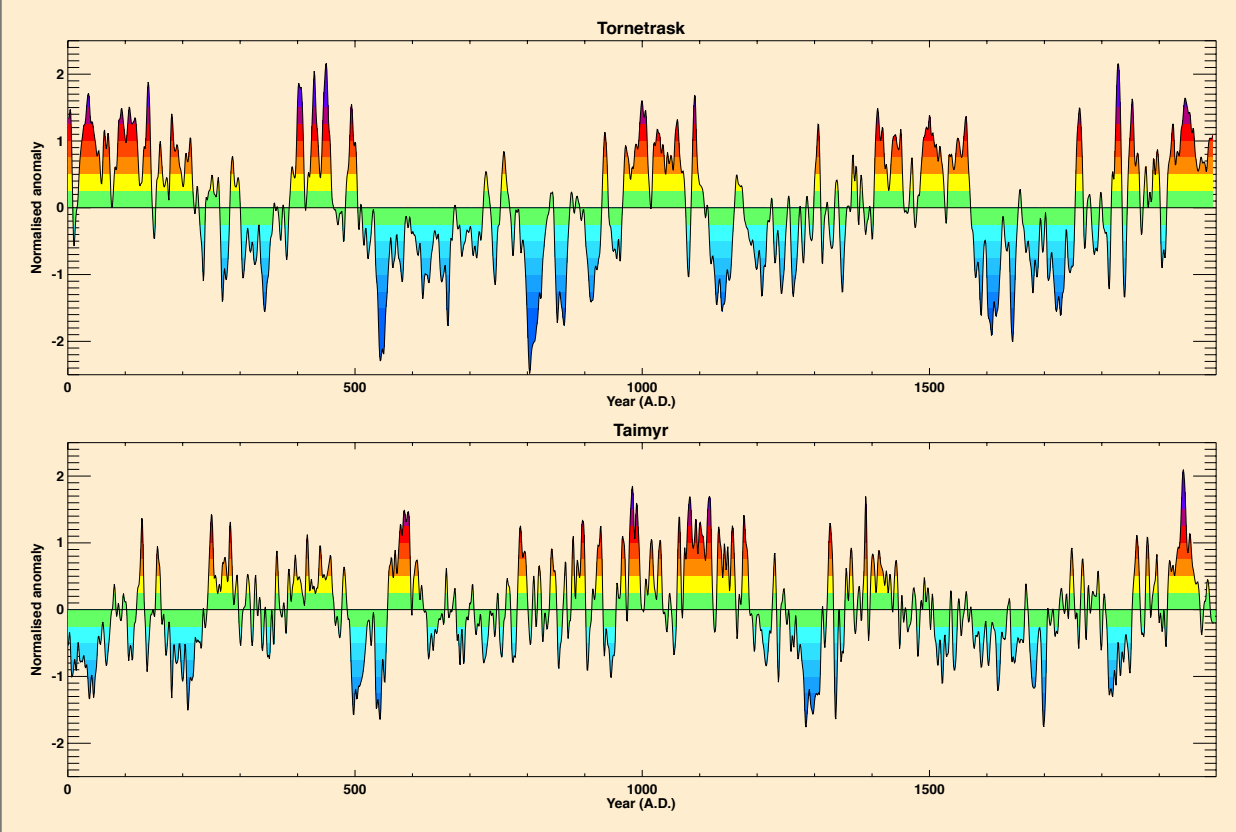

Examples of long sub-fossil ring-width chronologies presently under construction: these are from northern Sweden (Tornetrask) and Russia (Taimyr). The temperature-indicative data are expressed here as standardised anomalies from the 2000-year mean, smoothed to emphasise decadal and longer timescale variability.

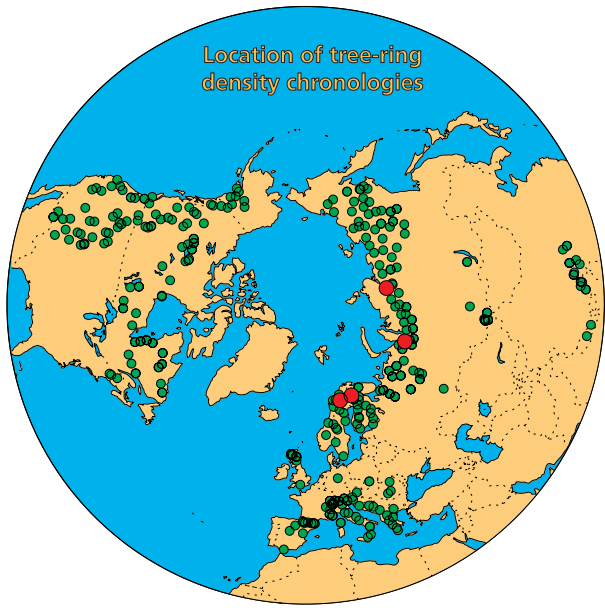

The present ADVANCE-10K tree-ring density network. The red circles show the locations of the long sub-fossil chronologies.

tions come from the region between the Finnish border and the Ural Mountains. There presently remains vast scope for expanding and improving the Russian densitometric database and the prospects for a rapid acceleration of this work have been boosted recently by the establishment of a new tree-ring densitometry facility, the first in Russia, at the Institute of Forest, Krasnoyarsk, made possible through the support of the European INTAS scheme.

Besides reconstructing maps of temperature variability, it has also been possible to provide a useful indication of very large scale mean temperature changes over the last 600 years by averaging the tree-ring density chronologies across the entire network. The resulting series provides strong evidence of the effect of different known volcanic eruptions, such as in 1453 (Kuwae, 1452); 1601 (Huaynaputina, 1600); 1642 (Mt. Parker, 1641) and 1816 and 1817 (Tambora, 1815) on Northern Hemisphere mean temperature. The data also suggest dates for probable, but as yet unattributed, large eruptions, such as that in 1695.

At a handful of high-latitude locations in northwest Sweden, northern Finland and on the Yamal and Taimyr peninsulas, Russia, ADVANCE-10K is working toward the construction of continuous ring-width chronologies that will provide unique regional evidence of annual, decadal and century timescale temperature changes, all 

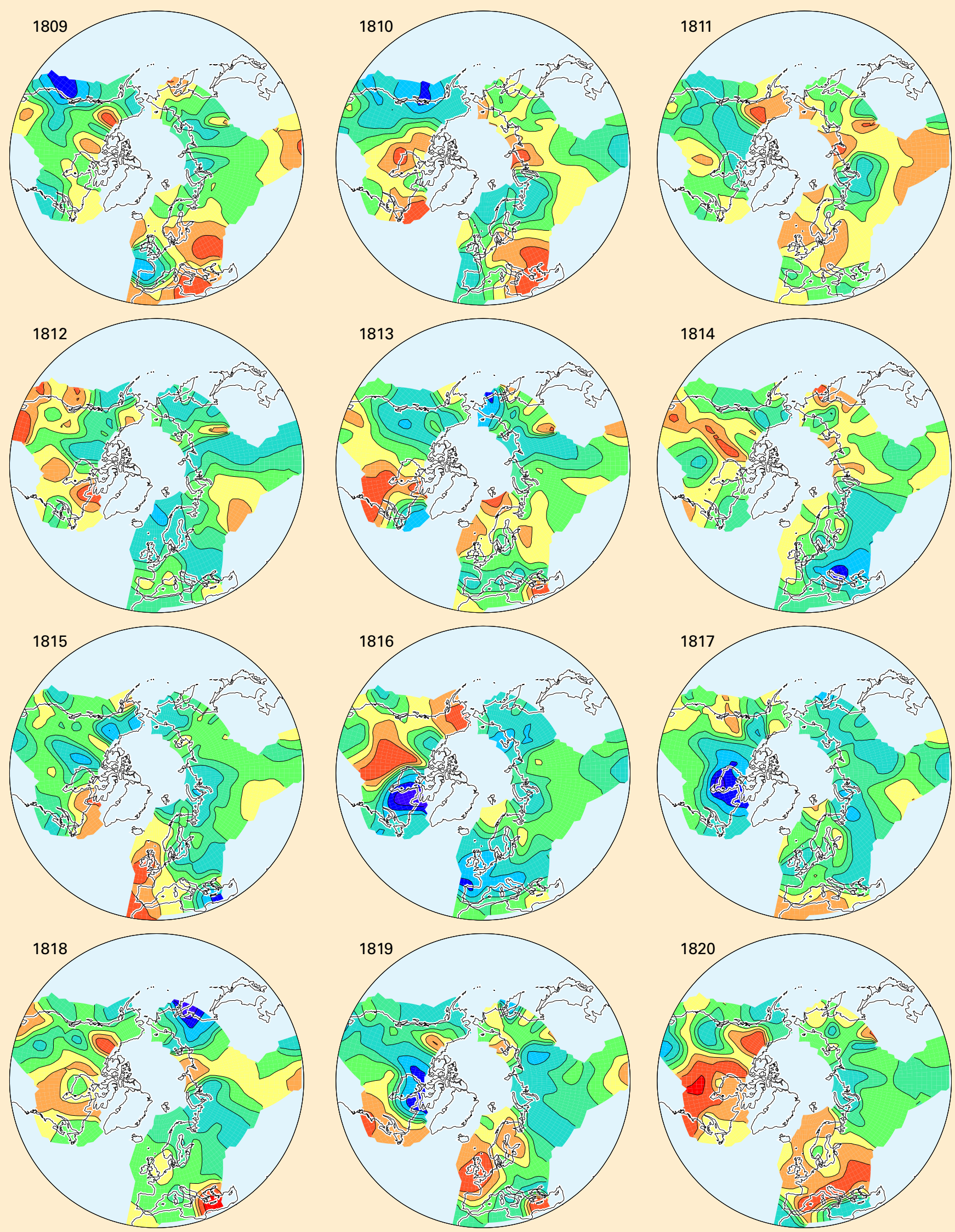

Normalised density anomaly

Tree-ring density anomaly maps indicating areas of relatively warm and cool summers during the early $19^{\text {th }}$ century. Over the hemisphere as a whole, 1810-1820 was one of the coolest decades of the millennium, in part due to the effects of large explosive volcanic eruptions in 1809 (known through ice acidity) and 1815. 
firmly dated to the exact year over many thousands of years. These are long-term projects, which ultimately depend on locating sufficient suitable sub-fossil wood samples whose ages span all periods of the full record. Continuous chronologies have been constructed for the last 2000 years at all locations. In Sweden and Finland, almost all of the preceding 5000 years is also complete, although a firm chronological link across the $3^{\text {rd }}$ and $4^{\text {th }}$ centuries B.C. is still to be established. In Yamal, the 'modern' continuous chronology extends over 4 millennia and much earlier material, as in Taimyr, is either already measured or awaits processing. The potential to produce 7000 to 8000 -year long series at all of these locations will be realized in the near future.

Further south, in central Europe, the project has brought together many thousands of oak ring-width series from historical, archaeological or sub-fossil origins that were previously dispersed in different dendrochronology laboratories in Sweden, Holland, Denmark, the United Kingdom, Germany and Poland. Several new regional 8000-year long chronologies have been constructed using objective clustering techniques. Temporal variability in the strength of interregional associations shown in these series, as well as detailed analysis of the extent of climate control of the chronology variability are underway.

Important work comparing tree-ring data collections located in Hohenheim and Göttingen has recently produced a corrected and extended absolutelydated oak series reaching back more than 10,000 years - the longest in the world - allowing an extension and revision of previous radiocarbon calibration curves.

Different phases of active oak germination and deposition throughout the Holocene have been identified in landgrown and bog contexts. There is also other evidence for the existence of notable environmental events such as a pronounced decrease in oak growth in the middle $6^{\text {th }}$ century A.D. that may be linked to very cool conditions seen in the high-northern trees in A.D. 536. Another low oak growth period lasted for about 100 years between 6270 and 6040 B.C., corresponding with the oxygen isotope evidence for contemporaneous cold in Greenland and Antarctic ice cores.

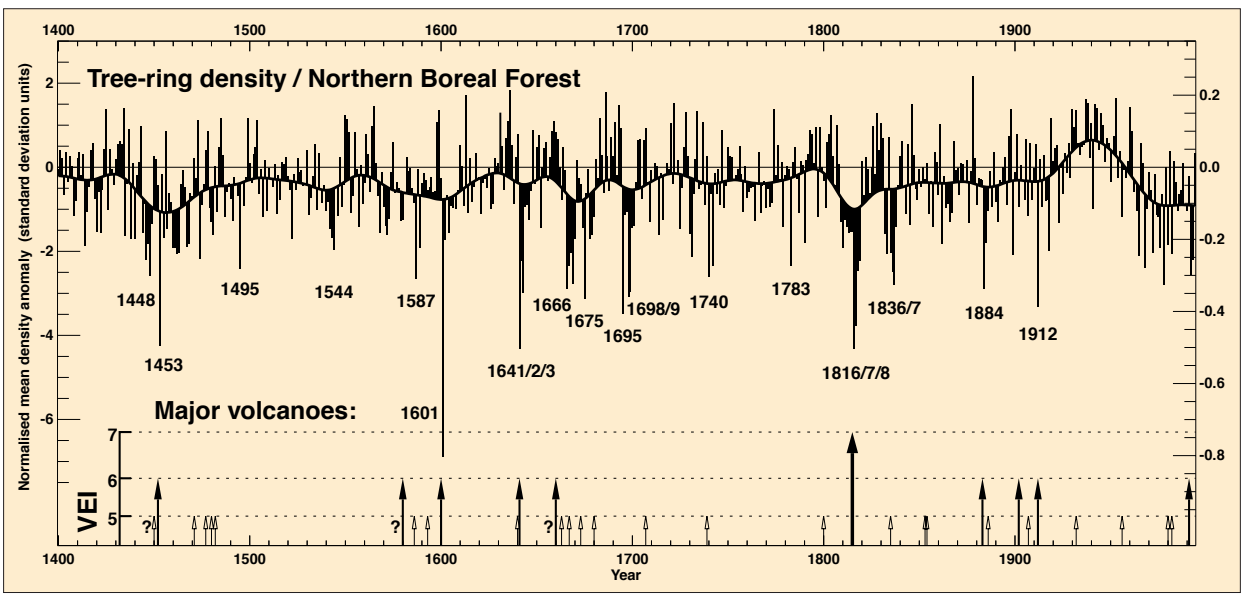

Averaging temperature-sensitive chronologies from around the hemisphere provides a precise record of interannual temperature variability demonstrating a clear link between cool summers and large explosive volcanic eruptions.

In the immediate future, work will continue on important statistical issues related to the processing and interpretation of all of the various tree-ring collections. Potential anthropogenic influences on recent tree growth will become an increasingly important focus of the work. Increased tree productivity during the $19^{\text {th }}$ and early $20^{\text {th }}$ centuries and post-1950 declines in tree density trends have recently been identified in our data. The extent, detail and implications of these phenomena have yet to be further explored. Chronology confidence and the expression of climate forcing are most strongly expressed on short (annual to century) timescales. New data processing techniques are exploring the reconstruction of longer period variability. This will require the extraction of common long-term growth trends from much larger regional data collections than are currently available. The precise reconstruction of tree line movements will become increasingly feasible and the potential for comparison and reconciliation with other long-term, though less well resolved, climate proxies extracted from ice, lake sediments, speleothems, or peat will become increasingly practical and important. This multiproxy work should contribute usefully to the aims of PAGES PEP III research as well as CAPE and PEP II.

Increased collaboration with, and support for, our Russian colleagues would enable a vital extension of the work in central and eastern Siberia. Furthermore, the development of North/ South transects of tree-ring data in central Siberia and Scandinavia would enhance the work of the IGBP terrestrial transects. Future work could also usefully incorporate active participation of workers engaged in ongoing work in the Himalayas as well as establish a firm tree-ring chronology in central Europe extending back into the Younger Dryas, some 12,000 years ago. Finally, better collaboration with other, including nonEuropean, dendroclimatologists and those synthesizing paleodata across the whole of the high-latitude and highelevation regions will continue to be sought.

A special issue of The Holocene, detailing the results of ADVANCE-10K, is scheduled for publication in late 1999. All of the primary data collected under this project, along with the regional chronologies and associated derived reconstructions will be made available through the World Data Center-A for Paleoclimatology.

For details of the aims, participants, publications or other information relating to ADVANCE-10K contact the author or visit our web site. ADVANCE$10 \mathrm{~K}$ is funded by the European Union under ENV4-CT95-0127: Scientific Officer $\mathrm{Ib}$ Troen.

\section{KeItH Briffa}

School of Environmental Sciences, University of East Anglia, Norwich, UK

k.briffa@uea.ac.uk

http://www.cru.ac.uk/cru/research/ 